Original paper available at

http://www.rsc.org/Publishing/Journals/CC/article.asp?doi=b000539h

DOI: 10.1039/b000539h

Chemical Communications, 2000, 761-762.

Synthesis and catalytic activity of Ti-ITQ-7: a new oxidation catalyst with a three dimensional system of large pore channels

María-José Díaz-Cabañas, Luis A. Villaescusa and Miguel A. Camblor*

Instituto de Tecnología Química (CSIC-UPV), Avda. Los Naranjos s/n, 46022 Valencia, Spain.

*Corresponding author: Miguel A. Camblor, current address: Instituto de Ciencia de Materiales de Madrid (CSIC), c/ Sor Juana Inés de la Cruz, 3, 28049 Madrid, Spain, e-mail: macamblor@icmm.csic.es 


\section{Synthesis and catalytic activity of Ti-ITQ-7: a new oxidation catalyst with a three dimensional system of large pore channels}

María-José Díaz-Cabañas, Luis A. Villaescusa* and Miguel A. Camblor*

Instituto de Tecnología Química (CSIC-UPV), Avda. Los Naranjos s/n, 46022 Valencia, Spain.

*Corresponding author; e-mail: macamblo@itq.upv.es

* Current address: School of Chemistry, University of St. Andrews, St. Andrews KY16 9ST, UK

Isomorphous substitution of Si by $\mathrm{Ti}$ in the framework of ITQ-7, the crystalline silica polymorph of lowest density, has been achieved by direct synthesis, affording its three dimensional system of large pore channels to be used in selective oxidation reactions.

After the discovery of the medium pore zeolite TS $-1^{1}$ and of its outstanding properties as a catalyst for the selective oxidation of organic compounds with aqueous hydrogen peroxide, ${ }^{2}$ the isomorphous substitution of Si by Ti in zeolites has received much attention. ${ }^{3}$ Aside for a fundamental interest in understanding the remarkable catalytic properties of TS-1, there has been a considerable effort in making new Ti-zeolites that could enlarge the field of application of these materials in industrially important oxidation reactions. Within this aim, the search for catalysts with larger pores allowing to process larger molecules and/or to use oxidising agents larger than $\mathrm{H}_{2} \mathrm{O}_{2}$ has been particularly relevant. New materials with larger pores such as zeolite Ti-Beta ${ }^{4}$ and the non-zeolite mesoporous Ti-MCM- $41^{5}$ were developed and their catalytic properties tested. Although those materials, particularly Ti-Beta, have clear advantages from the point of view of pore 
size, they are also intrinsically less active than TS-1. Very interestingly, Ti-Beta presents peculiar differences in catalytic properties when compared to TS-1 (with regard to catalytic behaviour in different solvents and selectivity in the epoxidation of olefins and in the hydroxylation of phenol) which appear to be due to the different crystalline structure of both materials ${ }^{6}$ rather than to differences in their hydrophobicity, Al content or degree of isolation of $\mathrm{Ti}$ in tetrahedral positions as initially assumed. Unfortunately, a detailed structural investigation of those differences is hindered by the very complex, severely intergrown nature of the structure of zeolite Beta. ${ }^{7}$ Here we present Ti-ITQ-7 (structure code ISV), a new three dimensional large pore zeolite which presents a more ordered structure than zeolite Beta. ${ }^{8}$ In addition to the opportunities that Ti-ITQ-7 may offer in the investigation of the structure/activity/selectivity relationships in Ti-zeolites, its distinct pore architecture could give rise to differences in its catalytic performance when compared to Ti-Beta.

Ti-ITQ-7 can be prepared in conditions similar to those described for the pure silica polymorph, ${ }^{8}$ by first cohydrolyzing tetraethylorthotitanate (TEOTi) and tetraethylorthosilicate (TEOS) in an aqueous solution of the hydroxide form of the structure directing agent (SDA) 1,3,3-trimethyl-6-azoniumtricycle[3.2.1.4 $\left.{ }^{6,6}\right]$ dodecane. Crystallites of ITQ-7 may be added as seeds to promote the crystallisation. In a typical synthesis $0.76 \mathrm{~g}$ TEOTi and $13.87 \mathrm{~g}$ TEOS were hydrolysed in $27.77 \mathrm{~g}$ of a solution of the hydroxide form of the SDA (1.0 moles/Kg). Then, $0.65 \mathrm{~g} \mathrm{H}_{2} \mathrm{O}_{2}$ (aq. $35 \%$ wt.) were added and the mixture was stirred at room temperature allowing evaporation of all the ethanol and of the water needed to obtain the final composition given below. Then, $1.38 \mathrm{~g} \mathrm{HF}$ (aq. $48 \%$ wt.) were added before the final addition of a suspension of $\mathrm{SiO}_{2}$ ITQ-7 crystallites in water ( $0.20 \mathrm{~g}$ zeolite, $2.50 \mathrm{~g}$ water). The final composition of the gel was $\mathrm{SiO}_{2}: 0.05$ $\mathrm{TiO}_{2}: 0.10 \mathrm{H}_{2} \mathrm{O}_{2}: 0.5 \mathrm{SDAOH}: 0.50 \mathrm{HF}: 3 \mathrm{H}_{2} \mathrm{O}$. The mixture was poured into PTFElined stainless steel autoclaves and crystallised under rotation at $150^{\circ} \mathrm{C}$ for 12 days (yield: 
27.48 g Ti-ITQ-7 per 100 g synthesis mixture; Si/Ti ratio of Ti-ITQ-7: 120). The solid presents the XRD pattern characteristic of zeolite ITQ-7 and, in order to remove its guest species, it can be calcined to $580^{\circ} \mathrm{C}$ without structural damage (Figure 1).

In the absence of seeds, the crystallisation of Ti-ITQ-7 in the presence of relatively high $\mathrm{Ti}$ contents $(\mathrm{Si} / \mathrm{Ti} \leq 30)$ do not proceed until completion: while the zeolite nucleates and starts growing, the crystallisation stops at certain point and the partially crystallised solid remains essentially unchanged by powder XRD even if heating is extended for an additional month. At present we don'thave a clear explanation for this observation, which appears difficult to rationalise given that Ti-ITQ-7 may be crystallised from gels with even higher Ti contents if seeds are used (see example above). For Si/Ti ratios of 50 or below in the starting gel, no seeds are required.

The isomorphous substitution of Si by Ti in the framework of ITQ-7 (the crystalline silica polymorph of lowest density known to date) ${ }^{8}$ has been confirmed by the usual techniques. The diffuse reflectance UV spectra of calcined Ti-ITQ-7 (Figure 2) show a band at 205-220 nm, typically assigned to a electronic transition with ligand to metal charge transfer character involving isolated $\mathrm{Ti}$ in the framework of zeolites. ${ }^{9}$ Only for $\mathrm{TiO}_{2}$ contents of $1.1 \%$ or above, the band has a tail at the high wavelength side which suggests the presence of a small amount of $\mathrm{TiO}_{2}$ anatase. The infrared spectra of the calcined materials in the region of framework vibrations show a band at $960 \mathrm{~cm}^{-1}$, characteristic of Ti-zeolites and assigned to the Si-O stretching in Si-O-Ti groups. ${ }^{10}$

The activity and selectivity of Ti-ITQ-7 in the selective epoxidation of 1-hexene with $\mathrm{H}_{2} \mathrm{O}_{2}$ was tested and compared to the performance of aluminium-free Ti-Beta synthesised in fluoride media ${ }^{6}$ (Table 1 ). Three main conclusions may be derived from the results in Table 1. First, the activity and selectivity of Ti-ITQ-7 for the oxidation of this alkene is equivalent to that of Ti-Beta with similar Ti content. Second, the activity of TiITQ-7 is much higher in acetonitrile than in methanol, in contrast to the known behaviour 
of TS-1, for which protic solvents work better, ${ }^{11}$ and much alike that of Ti-Beta. The better defined XRD pattern of ITQ-7 (Figure 1) compared to Beta might allow a more detailed structural study of the striking observation that Ti-zeolites with different structures perform much differently when used as catalysts in different solvents. And finally, the catalytic results support the conclusion, primarily derived from the characterisation results described above, that Ti has been successfully substituted for Si in the zeolite ITQ-7 framework.

Ti-ITQ-7 is the first high-silica zeolite catalyst with a three dimensional system of large pore channels circumscribed by windows of 12 tetrahedra since the discovery 30 years ago of the aluminosilicate zeolite Beta, ${ }^{12}$ and follows the very recent publication of the non-catalyst all-SiO 2 zeolite ITQ-7. ${ }^{8}$ Despite the much equivalent catalytic performance of Ti-ITQ-7 and Ti-Beta in the epoxidation of a small alkene such as 1hexene, the different pore architecture of both materials, specially in the crystallographic c direction (Figure 3), might give rise to differences in shape selectivity if a different, larger substrate of adequate shape is used.

Acknowledgements.- The authors greatly acknowledge financial support by the Spanish CICYT (project MAT97-0723). 


\section{References:}

1.- M. Taramasso, G. Perego and B. Notari, U.S. Patent 4,410,501, 1983.

2.- (a) D.R.C Huybrechts, L. De Bruycker and P.A. Jacobs, Nature, 1990, 345, 240; (b) B. Notari, Stud. Surf. Sci. Catal., 1991, 67, 243.

3.- G. Bellussi and M.S. Rigutto, Stud. Surf. Sci. Catal., 1994, 85, 177.

4.- (a) M.A. Camblor, A. Corma, A. Martínez and J. Pérez-Pariente, J. Chem. Soc. Chem. Commun., 1992, 589; (b) M.A. Camblor, A. Corma, A. Martínez, J. Pérez-Pariente and S. Valencia, Stud. Surf. Sci. Catal., 1994, 82, 531; (c) M.A. Camblor, M. Costantini, A.

Corma, L. Gilbert, P. Esteve, A. Martínez and S. Valencia, Chem. Commun., 1996, 1339. 5.- (a) P.T. Tanev, M. Chibne and T.J. Pinnavaia, Nature, 1994, 368, 321; (b) A. Corma, M.T. Navarro and J. Pérez-Pariente, J. Chem. Soc. Chem Commun., 1994, 147.

6.- T. Blasco, M.A. Camblor, A. Corma, P. Esteve, J.M. Guil, A. Martínez, J.A. PerdigónMelón and S. Valencia, J. Phys. Chem. A, 1998, 102, 75.

7.- J.M. Newsam, M.M.J. Treacy, W.T. Koetsier and C.B. de Gruyter, Proc. R. Soc. Lond. A, 1988, 420, 375; (b) J.B. Higgins, R.B. LaPierre, J.L. Schlenker, A.C. Rohrman, J.D. Wood, G.T. Kerr and W.J. Rohrbaugh, Zeolites, 1988, 8, 446.

8.- L.A. Villaescusa, P.A. Barrett and M.A. Camblor, Angew. Chem. Int. Ed., 1999, 38, 1997.

9.- A. Zecchina, G. Spoto, S. Bordiga, A. Ferrero, G. Petrini, G. Leofanti and M. Padovan, Stud. Surf. Sci. Catal., 1991, 69, 251.

10.- M.R. Boccuti, K.M. Rao, A. Zecchina, G. Leofanti and G. Petrini, Stud. Surf. Sci. Catal., 1989, 48, 133.

11.- (a) M. G. Clerici, G. Bellussi and U. Romano, J. Catal., 1991, 129, 159; (b) M.G. Clerici and P. Ingallina, J. Catal, 1993, 140, 71.

12.- R.L. Wadlinger , G.T. Kerr, E.J. Rosinski, US Patent 3308069, 1967. 
Table 1. Results of the selective oxidation of 1-hexene with $\mathrm{H}_{2} \mathrm{O}_{2}$ over Ti-ITQ-7 and Ti-Beta $^{a}$

\begin{tabular}{llllll}
\hline Material & $\% \mathrm{TiO}_{2}$ & Solvent & 1-hexene & \multicolumn{2}{l}{ selectivity (\%) } \\
\cline { 5 - 6 } \cline { 5 - 5 } & & & conversion (\%) & Epoxide & $\mathrm{H}_{2} \mathrm{O}_{2}{ }^{\mathrm{b}}$ \\
\hline Ti-ITQ-7 & 0.30 & $\mathrm{CH}_{3} \mathrm{OH}$ & 1.7 & 100 & 76 \\
Ti-ITQ-7 & 0.30 & $\mathrm{CH}_{3} \mathrm{CN}$ & 8.8 & 100 & 100 \\
Ti-ITQ-7 & 1.14 & $\mathrm{CH}_{3} \mathrm{CN}$ & 27.1 & 100 & 89 \\
Ti-Beta & 0.76 & $\mathrm{CH}_{3} \mathrm{OH}$ & 7.6 & 91 & 100 \\
Ti-Beta & 0.76 & $\mathrm{CH}_{3} \mathrm{CN}$ & 12.9 & 100 & 100 \\
Ti-Beta & 1.40 & $\mathrm{CH}_{3} \mathrm{OH}$ & 20.0 & 50 & 98 \\
Ti-Beta & 1.40 & $\mathrm{CH}_{3} \mathrm{CN}$ & 39.2 & 100 & 100 \\
\hline
\end{tabular}

${ }^{\mathrm{a}}$ Batch reactor, $50^{\circ} \mathrm{C}, 17 \mathrm{mmol}$ 1-hexene, $11.8 \mathrm{~g}$ solvent, $0.4 \mathrm{~g} \mathrm{H}_{2} \mathrm{O}_{2}$ (35\%, wt.), $100 \mathrm{mg}$ catalyst, 7 hours. The Ti-Beta catalysts were prepared according to reference [6]. ${ }^{b} \mathrm{H}_{2} \mathrm{O}_{2}$ selectivity is defined as moles of oxidized products (epoxide and glycols) per 100 moles of $\mathrm{H}_{2} \mathrm{O}_{2}$ consumed in the reaction. 
Figures

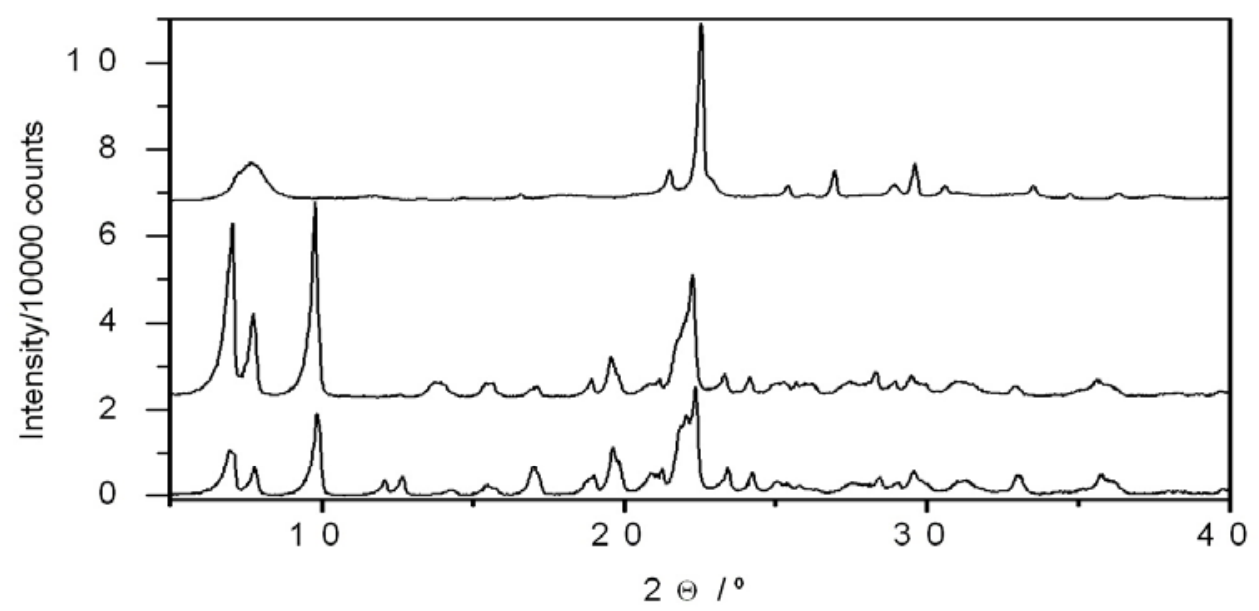

Figure $1 \mathrm{X}$ ray diffractograms of (from bottom to top) as-made and calcined Ti-ITQ-7 and as-made Ti-Beta ( $\mathrm{TiO}_{2}$ contents: 1.24, 1.24 and 1.40\%). 


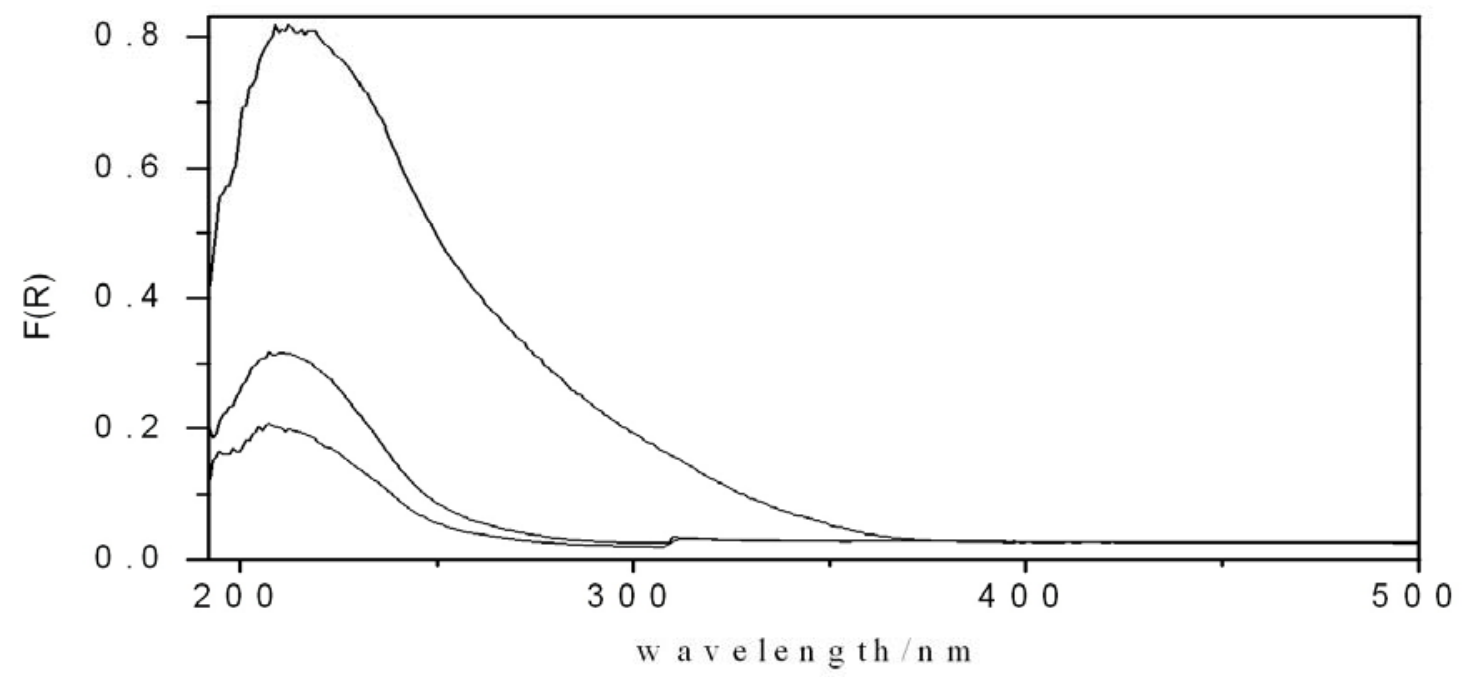

Figure 2 Diffuse reflectantance ultraviolet-visible absorption spectra of calcined Ti-ITQ-7 with (from bottom to top) $0.15,0.31$ and $1.24 \% \mathrm{TiO}_{2}$. 

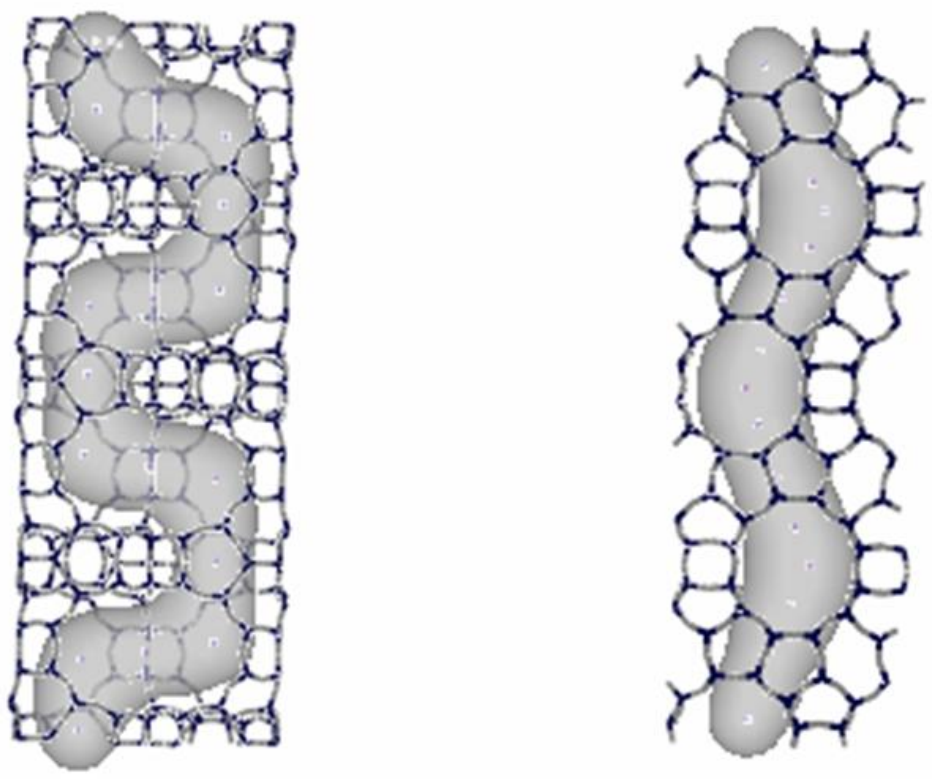

Figure 3 Comparison of the non-linear large pore channels running along the [001] direction of ITQ-7 (ISV, left) and one of the polymorphs of zeolite Beta (*BEA, right). The frameworks, depicted in a stick model, are viewed in projection down the [110] (ISV) or [100] direction (BEA) to show the largest deviation from linearity of the [001] channels, which are drawn as gray tubes. Both structures present also linear large pore channels (not emphasized in the figure) running along the [100] and [010] crystallographic directions. 


\section{Graphical Abstract}

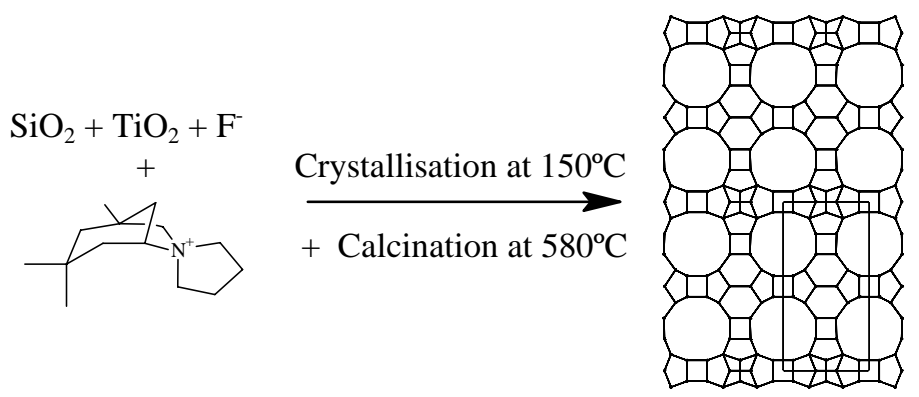

